\title{
STRATEGI PENGEMBANGAN PARIWISATA MELALUI MEDIA
}

\author{
Yusuf Adam Hilman \\ Prodi Ilmu Pemerintahan, Universitas Muhammadiyah Ponorogo \\ Jl. Budi Utomo no.10 Siman Ponorogo Jawa Timur Indonesia.
}

(545471adamongis@gmail.com / adamhilman@umpo.ac.id)

\begin{abstract}
ABSTRAK
Pembangunan pariwisata di Jawa Timur bisa dijadikan sebagai salah satu contoh, bagaimana pengelolaannya menggunakan beberapa strategi, yang bisa diukur dan juga dievaluasi secara berkesimbungan, diantaranya: Membuat kebijakan pariwisata yang terintegrasi di daerah mulai tingkat Kabupaten/kota hingga pedesaan, supaya stakeholder, masyarakat, dan pengusaha (Private sector) bisa bersinergi, dalam proses pembuatan kebijakan sehingga nantinya kebijakan yang dibuat, bisa kuat dan dukunganpun mengalir dari semua pihak, Membangun Brand Tourism untuk mengembangkan wisata lokal, Membuat event wisata tahunan, sebagai bentuk publikasi dalam upaya untuk memperkenalkan potensi daerah, Membangun sarana transportasi, jalan, dan angkutan untuk mempermudah aksesbilitas, para pelancong guna mencapai destinasi wisata yang dituju. Hasilnya bisa kita saksikan, bagaimana Provinsi Jawa Timur Akhirnya berhasil, mengembangkan daerahnya dengan potensi yang dimiliki, dengan bukti bahwa ada peningkatan pengunjung ke Jawa Timur, serta tingginya perolehan pendapatan dari sektor wisata, membangun band Image serta meembuat even wisata menjadi kunci penting, yang membuat geliat pariwisata di Jawa Timur banyak menarik simpatik wisatawan baik regional maupun internasional.
\end{abstract}

Kata Kunci:

Strategi, Pengembangan Wisata, Media

\begin{abstract}
Development of tourism in east java it can be used as one example, how funds employ few specific strategies, who can be measured and is also assessed in qontinues, including: Made a policy tourism integrated at areas have started the district level to rural, that stakeholders, the community, and businessman (private sector) be synergy, in the process of making policy which in turn the policy made, can strong and sporting flow from all parties, Build brand tourism to develop local tourism, Make tourism annual event, as a form of publication in the quest to introduce the potential of the region, Make to transportation, The way, and transportation to ease accessibility of, the travelers to achieve a tourist destination that intended. So it was we see, how the province of east java finally made it, develop the region to potentials owned, with proof
\end{abstract}


that there is an increase of visitors to East Java, and the high income of tourism sector. Image building and make to band even be the key travel, which makes stretching tourism in East Java, many sympathetic attract tourists both regionally and internationally.

Keywords:

Strategy, Development, Tourism, Media.

\section{PENDAHULUAN}

Indonesia merupakan salah satu negeri indah di muka bumi, karunia Tuhan yang luar biasa, hal tersebut karena memiliki potensi yang menakjubkan, diantaranya: kekayaan alam, berupa: gunung, laut, hutan, selain itu Indonesia juga memiliki keragaman budaya yang kemudian berkembang pada titik dimana kebudayaan tersebut membentuk karakteristik, corak, serta pola prilaku masyarakatnya dalam kehidupan sehari - hari. Hal ini yang kemudian menciptakan, kebudayaan dalam berbagai bentuk, seperti: seni tari, seni musik, adat - istidat, hingga lahir berbagai macam kudapan lezat yang menjadi kuliner khas di sebuah daerah, fakta inilah yang menurut saya, menjadikan Indonesia sebagai negeri dongeng, atau surga kecil yang ada di dunia.

Secara spesifik Keindahan Indonesia dapat dilihat pada Letak astronomis yang membujur $6^{\circ} \mathrm{LU}$ (Lintang Utara) - $11^{\circ} \mathrm{LS}$ (Lintang Selatan) dan antara $95^{\circ} \mathrm{BT}$ (Bujur Timur) - $141^{\circ} \mathrm{BT}$ (Bujur Timur). Sehingga membuat Indonesia beriklim tropis, dengan persebaran sinar matahari setiap tahun dan hanya terdapat dua kali pergantian musim dalam setahun yakni musim kemarau dan musim hujan. (diakses dari http://www. artikelsiana.com/2015/08/letak-geografisastronomis-geologis.html pada 11 Agustus 2016)

Gambaran itulah yang memberikan penjelasan tentang mengapa Indonesia tumbuh sebagai negeri yang amat subur dan makmur, dengan berbagai potensi yang dapat dioptimalkan, guna memenuhi seluruh hajat hidup masyarakatnya.
Pemetaan potensi yang dimiliki oleh negeri ini membentang luas, mulai dari ujung gugusan kepulauan Sumatra hingga Provinsi Papua, berisikan potensi laut (bahari) dan juga dataran yang dihiasi oleh pegunungan - pegunungan yang subur dengan hasil buminya, seperti: padi, jagung, sagu, ikan laut, dan masih banyak lainnya. Selain itu, Indonesia juga memiliki panorama - panorama cantik yang sayang jika kita dilewatkan.

Keindahan Indonesia tidak hanya berhenti sampai disitu, bangsa Indonesia sejak dulu kala sudah dikenal sebagai bangsa yang ramah, bersahaja, serta memiliki kearifan lokal, yang membuat kehidupan masyarakatnya selalu bersinergi dengan alam dan sang maha Pencipta.

Berbicara tentang ke-Indonesia-an, seperti penuturan diatas, maka tidak akan pernah selesai, terutama terkait dengan bagaimana memanfaatkan potensi lokal yang dimiliki, ulasan tersebut begitu menarik untuk dikaji secara komperhensif, kendati demikian, masih banyak yang tidak sadar akan potensi yang dimiliki, atas dasar tersebut penulis berupaya, mengurai keberhasilan daerah - daerah dalam memanfaatkan potensi, tanpa harus mengeksploitasi potensi dengan cara - cara yang tidak bijak.

Wilayah - wilayah di penjuru negeri ternyata, sudah banyak yang bisa membaca peluang dan juga mengoptimalkan potensi tersebut, kemudian mengemasnya dalam berbagai kegiatan pariwisata, yang jelas dari aktifitas tersebut pada akhirnya akan menimbulkan multiple effect atau efek ganda, yaitu menjaga kelestarian potensi lokal yang dimiliki, sekaligus dapat meningkatkan 
pendapatan masyarakat, untuk kesejahteraan bersama.

Provinsi Jawa Timur merupakan salah satu wilayah yang gencar melakukan berbagai pengembangan potensi alam dan budaya untuk kegiatan pariwisata, upaya tersebut dilakukan melalui manajemen pariwisata yang baik, upaya - upaya tersebut bisa dilihat dari keberhasilannya, melalui indicator jumlah kunjungan, serta meingkatnya pendapatan dari sektor pariwisata tahun ke tahun.

Jumlah wisman Januari - Juni 2016 mencapai 95.850 kunjungan atau naik sebesar 1,83 persen dibanding jumlah wisman periode yang sama tahun 2015 yang mencapai 94.129 kunjungan. (diakses dari http://jatim.bps.go.id/Brs/view / id/394 pada 11 Agustus 2016)

Gubernur Jawa Timur, Soekarwo, mengungkapkan, pertumbuhan kinerja pariwisata di Jawa Timur pada tahun 2014 menunjukkan pertumbuhan yang signifikan. Indikator yang bisa dilihat adalah kinerja kunjungan wisatawan mancanegara meningkat 54,07\% dibanding tahun 2013. "Ini angka riil, kunjungan wisatawan mancanegara ke Jawa Jawa Timur sebanyak 463.596 ribu orang pada tahun 2014. Sedangkan di tahun 2013 adalah 300.909 orang. Itu artinya meningkat 54,07\% dibanding tahun 2013," Kata Soekarwo. Menurut Gubernur, jumlah pergerakan wisatawan nusantara sebanyak 45,61 juta orang atau meningkat $14,94 \%$ dari tahun sebelumnya. Disamping itu Produk Domestik Regional Bruto sektor pariwisata tahun 2014 sebesar Rp 101,97 triliun. Di tahun 2013 sebesar Rp 88,16 triliun. (Diakses dari http:/ / bappeda.jatimprov. go.id/2015/05/08/pdrb-dari-sektor-pariwisataharusnya-lebih-bisa-diandalkan/ pada 11 Agustus 2016)

Upaya tersebut tentunya tidak hanya dilakukan secara sendiri tetapi melalui kegiatan bersama yang melibatkan, beberapa daerah, mulai dari tingkat Desa hingga Kabupaten dan Kota.
Provinsi Jawa Timur pada tahun 2015 memiliki sekitar 29 Kabupaten, 9 Kota dengan jumlah kecamatan sekitar 664, 5674 Desa, dan 2827 Kelurahan. (diakses dari http://jatim.bps. go.id/linkTabelStatis/view/id/346 pada 11 Agustus 2016)

Potensi kelembagaan dari sistem pemerintahan yang dimiliki oleh Provinsi Jawa Timur, merupakan salah satu kuncinya, mengingat Jawa Timur memiliki luas daerah dan persebaran daerah yang paling banyak di Indonesia.

Upaya itu selain harus bisa mempertemukan berbagai kepentingan, disini juga diperlukan komunikasi yang intensif oleh semua pihak, caranya dengan membuat sebuah strategi penataan Pariwisata dapat di ukur dan dievaluasi, langkah - langkah tersebut, dapat dijelaskan sebagai berikut. Caranya adalah: 1). Membuat kebijakan pariwisata yang terintegrasi di daerah mulai tingkat Kabupaten/ kota hingga pedesaan, supaya stakeholder, masyarakat, dan pengusaha (Private sector) bisa bersinergi, dalam proses pembuatan kebijakan sehingga nantinya kebijakan yang dibuat, bisa kuat dan dukunganpun mengalir dari semua pihak, 2). Membangun Brand Tourism untuk mengembangkan wisata lokal, 3). Membuat event wisata tahunan, sebagai bentuk publikasi dalam upaya untuk memperkenalkan potensi daerah, 4).Membangun sarana transportasi, jalan, dan angkutan untuk mempermudah aksesbilitas, para pelancong guna mencapai destinasi wisata yang dituju.

Pentingnya manajemen pariwisata, akan meminimalisir, serta mengurangi resiko dari ketidak efektifan sebuah strategi, karena Tujuan utama yang ingin di capai adalah terjalinanya kerjasama anta lini, serta optimaliasi publikasi terkait pewartaan obyek - obyek pariwisata yang ada di wilayah Jawa Timur..

Indikasi tersebut, menegaskan bahwa penataan pariwisata di Provinsi Jawa Timur, memang benar - benar mulai menuai buah yang manis, mengingat pertumbuhan pendapatan 
dari sektor pertanian meningkat, dan di Indikasikan dengan meningkatnya pendapatan masyarakat.

Di sisi lain menurut Budiyanto (2005) dan M. Syoim dan Fadli M (2004) penerapan otonomi daerah mendorong upaya pengembangan potensi daerah dalam rangka peningkatan pendapatan daerah untuk kesejahteraan masyarakat. (Moch. Agus Krisno Budiyanto Batu 2010)

Penelitian ini, secara umum ingin mengupas, tentang bagaimana strategi pariwisata itu dilaksanakan, hingga menjadi sebuah produk pariwisata yang berkualitas.

Pemanfaatan media serta pembuatan brand image, merupakan salah satu bentuk strategi yang biasa dikembangkan, guna memaksimalkan penataan pariwisata di Jawa Timur supaya menjadi lebih efektif.

\section{PEMBAHASAN}

Konsep penataan Pariwisata yang ideal, seperti penegasan diatas, dapat dilakukan dengan beberapa langkah strategis yang telah dirumuskan oleh penulis, dari hasil pembacaan pengelolaan pariwisata di Provinsi Jawa Timur.

Langkah pertama yakni, Membuat kebijakan pariwisata yang terintegrasi di daerah mulai tingkat Kabupaten/kota hingga pedesaan, guna meningkatkan mobilisasi yang memudahkan daerah untuk mengembangkan potensi pariwisata.

Pemerintah Jawa Timur melalui Peraturan Gubernur no.85 tahun 2008, telah membuat uraian tugas sekertariat, bidang, sub bagian dan seksi dinas kebudayaan dan pariwisata, yang memiliki tugas dan lingkup kerja yang spesifik, yang mengatur tata urusan di bidang pariwisata.

Daerah - daerah di Provinsi Jawa Timur juga melakukan komunikasi dan membuat kebijakan kerjasama dengan berbagai pihak untuk mengembangkan pariwisata, di daerah - daerah masing, masing seperti yang dilakukan oleh Kabupaten Lamongan.

Distribusi kewenangan dari pusat ke otonomi daerah (desentralisasi) yang disebabkan daerah harus lebih mandiri dalam segala bisnis pemerintah mereka. Dalam peningkatan pendapatan daerah, pariwisata merupakan daya tarik tertentu, di mana pengembangan sektor pariwisata adalah hal yang harus dipertimbangkan dalam cara yang logis dan realistis. Karena pariwisata bisa dikategorikan ke dalam kelompok industri terbesar, di mana 8 persen barang dan ekspor jasa berasal dari sektor pariwisata. Pariwisata merupakan salah satu sektor pembangunan yang terus dikembangkan baik oleh pemerintah pusat dan pemerintah daerah. Ini karena, pariwisata memainkan peran penting dalam pembangunan Indonesia, terutama sebagai penghasil Negara dan pendapatan daerah.(Muhammad Chusnul Khitam 2012)

Rekam jejak itu menegaskan bahwa Provinsi Jawa Timur memiliki keterbukaan terhadap semua pihak, yang ingin membantu dalam upaya mengembangkan potensi pariwisata di tingkat Kabupaten, Kota, hingga desa.

Konsep yang kedua menjelaskan tentang pembuatan Brand Tourism untuk mengembangkan wisata lokal, agar mempermudah pelancong mengenali potensi wisata yang ada di wilayah Jawa Timur.

Pengembangan industri ekotourisme berdasarkan indikator The International Ecotourism Society dan Mader di Kota Batu sudah termasuk baik. Hal ini dikarenakan dari indikator pengembangan industri ekotourisme menurut The International Ecotourism Society dan Mader secara umum telah direncanakan dikembangkan dengan baik dalam perpektif kebijakan. Dalam upaya mengembangkan industri ekotourisme Kota Batu, maka diperlukan koordinasi, kerja keras berbagai pihak untuk mengimplementasikan kebijakan pengembangan industri ekotourisme yang terdokumentasi dalam Rencana Induk 
Pengembangan Pariwisata Daerah (RIPPDA) Kota Batu dan Rencana Tata Ruang Wilayah (RTRW) Kota Batu. (Moch. Agus Krisno Budiyanto Batu 2010)

City branding berpengaruh signifikan terhadap city image sebesar 0,585. Semakin baik city branding Kota Batu maka akan berdampak pada meningkatnya city image Kota Batu di mata wisatawan. City branding berpengaruh signifikan terhadap keputusan berkunjung sebesar 0,237, artinya jika city branding Kota Batu ditingkatkan maka akan berdampak pada meningkatnya kunjungan wisatawan ke Kota Batu.(Wandari 2014)

City Branding atau Brand Image sebuah wilayah akan mempengaruhi stigma dan keinginan berkunjung wisatawan ke sebuah daerah, dan kota Batu Jawa Timur membuktikan hal itu, sehingga banyak kota maupun kabupaten melakukan strategi tersebut.

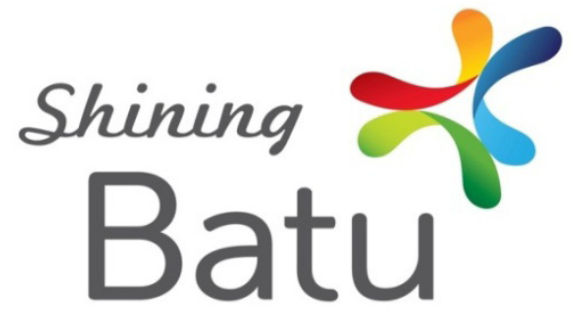

Gambar 1.

Shining Batu

Sumber dari: www.batukota.go.id

Strategi yang ketiga adalah membuat event tahunan yang bisa, dijadikan sebagai alternatif kunjungan wisata, sehingga pelancong bisa memilih agenda wisata yang ingin diikuti.
Beberapa daerah di Jawa Timur yang memeiliki agenda tahun, diantaranya: Jember, Ponorogo.

JFC juga cenderung menerapkan event branding, bahkan country branding. Serta dalam proses city branding yang dilakukan tidak terlepas dari political factor. Sehingga city branding Kabupaten Jember yang dilakukan belum sepenuhnya berhasil, dan hanya berhenti pada tataran promotion, tourism, dan profit oriented.(Cahyani 2008)

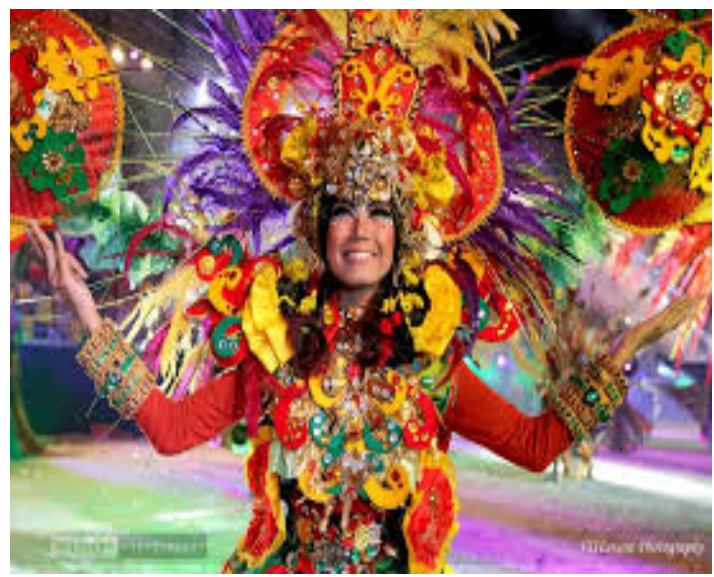

Gambar 2.

Jember Fashion Carnaval

Sumber dari: jemberkab.go.id

Upaya pemerintah daerah bekerja sama dengan masyarakat adalah dengan mendirikan sanggar - sanggar kesenian Reog, padepokan Reog dan dengan mendirikan paguyuban paguyuban Reog dan secara rutin mengadakan latihan bersama ataupun dengan mengadakan pementasan Reog.(Turhumawati 2008)

Kedua contoh ini hanya beberapa even tahunan yang diselenggarakan daerah untuk meningkatkan kunjungan pelancong ke daerah Jawa Timur, efeknya dapat memberikan suguhan yang spektakular bagi para wisatawan, sehingga tertarik untuk dating kembali. 


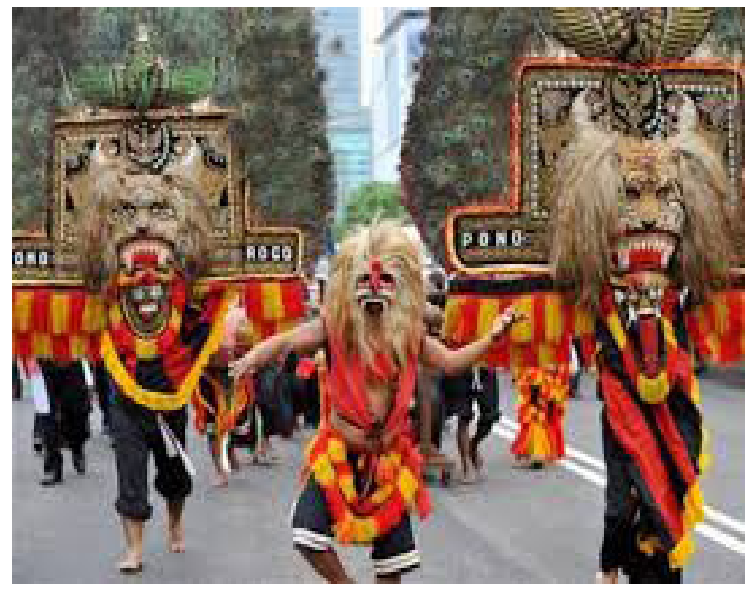

Gambar 3.

Festival Reog

Sumber dari: wwww.Ponorogo.go.id

Strategi yang terakhir adalah dengan Membangun sarana transportasi, jalan, dan angkutan untuk mempermudah aksesbilitas, para pelancong guna mencapai destinasi wisata yang dituju.

Berdasarkan hasil penelitian maka dapat disimpulkan hl-hal sebagai berikut: (1) Kota Batu memiliki potensi sumberdaya alam dan sosial yang baik sebagai modal pengembangan kota; (2) Kota Batu merupakan tempat refreshing dan beristirahat yang baik, jika dikemas secara baik dan terintegrasi, maka Kota Batu sebagai kota Wisata sangat mungkin untuk diwujudkan; (3) Sikap masyarakat sangat positif dan mendukung pengembangan kota Batu sebagai kota Wisata, sedangkan pola hubungan antara perilaku manusia dan lingkungan dalam konteks pengembangan dan pengelolaan lingkungan Kota Batu sebagai kota wisata dengan pola hubungan gabungan antara pola individu dapat menggunakan lingkungannya, individu berpartisipasi (ikut serta) dalam pengelolaan lingkungannya, serta individu menyesuaikan diri dengan lingkungannya; (4) Arah kebijakan pembangunan kota Batu berdasarkan dari Pola Dasar Pembangunan Kota Batu yang memuat komitmen arah kebijakan pembangunan daerah yang didasarkan pada kondisi, potensi, permasalahan dan kebutuhan nyata daerah, serta aspirasi masyarakat. Sedangkan Visi Kota Batu adalah: "Batu, Agropolitan Bernuansa Pariwisata dengan Masyarakat Madani"; (5) Arah pengembangan Kota Batu: ke Arah Utara, Barat Laut, Timur Laut dan Barat Daya; pengembangan pada kawasan Lindung dan Pengembangan pada kawasan budidaya untuk jenis kegiatan pertanian. Sedangkan kearah Barat, Timur dan Tenggara adalah fokus pada pengembangan pada kegiatan perkotaan; (6) Berdasarkan paradigma perkembangan kota, maka model pengembangan kota Batu sebagai kota ekowisata mengikuti paradigma perkembangan yang berorientasi Rurban Oriented Paradigm (ROP).(Sukmana 2009)

Melihat 4 strategi yang sudah dijabarkan diatas, perlu kita pahami bahwa kesemua langkah, itu merupakan daya upaya semua komponen masyarakat dalam rangka mewujukan tata kelola pariwisata yang berkesinambungan sehingga dapat memberikan dampak terhadap keberlanjutan sebuah daerah, sehingga daerah yang mampu melakukan perencanaan, pelaksanaan dan evaluasi menjadi penting, mengingat sektor pariwisata menjadi penting jika benar - benar ingin dikelola secara serius, guna meningkatkan kualitas kehidupan masyarakat khususnya dibidang kelestarian potensi dan meningkatkan pendapatan masyarakat.

\section{PENUTUP}

Strategi pengembangan pariwisata di Provinsi Jawa Timur, dititikberatkan pada pengoptimalisasian kerjasama antar lembaga dan juga kekuatan media, agar kegiatan pariwisata dapat berhasil dan bisa direspon secara cepat oleh khalayak. 


\section{DAFTAR PUSTAKA}

Cahyani, Istiqlaliah Dian. 2008. "Implementasi Jember Fashion Carnaval Sebagai Bagian Dari City Branding Kabupaten Jember." Commonline Departemen Komunikasi 3(2): $142-56$.

Moch. Agus Krisno Budiyanto Batu. 2010. "Kota Batu Provinsi Jawa Timur Dalam Perspektif." Jurnal Teknik Industri, 11(Pariwisata): 35-41.

Muhammad Chusnul Khitam. 2012. “| 333 Kerjasama Antara Pemerintah Daerah, Swasta, Dan Masyarakat Dalam Pengembangan Pariwisata (Ekbis Vi (1): 333-49.

Sukmana, Oman. 2009. “Model Pengembangan Lingkungan Kota Ekowisata (Studi Di Wilayah Kota Batu)." Humanity V (September): 42-47.

Turhumawati, Sasana Tunggal. 2008. “Kesenian Reog Sebagai Daya Tarik Wisata Budaya Di Kabupaten Ponorogo." Uns (Pariwisata).
Wandari, Lita Ayu. 2014. "Pengaruh City Branding' Shining Batu' Terhadap City Image Dan Keputusan Berkunjung Wisatawan Ke Kota Batu Tahun 2014." Jurnal Administrasi Bisnis 16(Pariwisata): 1-6.

http:/ / www.artikelsiana.com/2015/08/letakgeografis-astronomis-geologis.html pada 11 Agustus 2016.

http://jatim.bps.go.id/Brs/view/id/394 pada 11 Agustus 2016

http:/ /bappeda.jatimprov.go.id/2015/05/08/ pdrb-dari-sektor-pariwisata-harusnyalebih-bisa-diandalkan/ pada 11 Agustus 2016.

http://jatim.bps.go.id/linkTabelStatis/view/ id/346 pada 11 Agustus 2016

jemberkab.go.id pada 11 Agustus 2016.

www.batukota.go.id pada 11 Agustus 2016.

www.Ponorogo.go.id pada 11 Agustus 2016. 